\title{
O AtLÂNTICo enfermo e os Agentes dA SAÚDE NO PERÍODO DO TRÁFICO ILEGAL
}

BARCIA, Manuel. The Yellow Demon of Fever: Fighting Disease in the Nineteenth-Century Transatlantic Slave Trade. New Haven: Yale University Press, 2020. 269p.

Não é necessário ser especialista para saber que o tráfico de pessoas escravizadas entre o continente africano e as Américas, ao longo dos séculos, foi um mar de horrores em termos sanitários, dentro e fora das embarcações. Nem é coincidência que os navios que transportavam esses africanos e africanas para a venda na outra costa do Atlântico fossem chamados de tumbeiros. Mas, além da dor e da desumanização de suas vítimas, a viagem negreira foi também uma experiência sobre o conhecimento das doenças que se manifestavam durante a travessia. Foi também o terreno em que diferentes tratamentos daquelas enfermidades puderam se desenvolver para salvar vidas.
Para os traficantes, tratava-se de evitar a perda de suas "mercadorias", para não encontrarem prejuízo ao fim da arriscada empreitada. Isso não impediu a irrupção de diferentes doenças a bordo dos navios, resultantes do "imperialismo ecológico" - como denominou Alfred Crosby os impactos ambientais causados pela expansão marítima europeia -, que afetava a todos os envolvidos, causando elevadíssimas taxas de mortalidade e exigindo a presença dos mais variados especialistas ou "práticos da saúde". Como afirma o autor da obra aqui resenhada, os eventuais decréscimos na mortalidade de cativos durante a travessia raramente tiveram relação direta com as inovações médicas. No 
entanto, ao longo dos séculos, médicos, cirurgiões, boticários, contramestres, sangradores, barbeiros, entre outros, agiram na tentativa de curar, produzindo conhecimentos sobre a saúde, ainda que empíricos e fragmentados, formulados nas mais diversas tradições medicinais, incluindo a africana.

O livro de Manuel Barcia, professor da universidade de Leeds e estudioso da história atlântica e do tráfico, procura iluminar justamente esses práticos/praticantes da saúde (health practioners), voltando sua atenção para os de origem africana. Invariavelmente invisibilizados ou colocados em segundo plano pela medicina oficial, os saberes africanos de cura foram, no entanto, responsáveis pela criação conjunta de conhecimentos sobre $\mathrm{o}$ tratamento das várias doenças. Com uma denominação indiferenciada sobre os “práticos da saúde”, o autor enfatiza que, a despeito das hierarquias criadas por critérios da medicina ocidental, ocorreu uma intensa circulação de saberes, formando uma medicina de “zonas de contato”, para utilizar a expressão de Mary Louise Pratt.

Percorrendo uma vasta historiografia transatlântica do tráfico,
Manuel Barcia enfoca o problema da saúde em um período em que o comércio negreiro se tornara ilegal. A partir da abolição do tráfico pela Inglaterra em 1807, sobretudo com a atuação das Comissões Mistas para a Supressão do Tráfico de Escravos envolvendo aquele país e vários outros, o autor argumenta que houve uma relativa piora nas condições de transporte dos africanos traficados. Com efeito, historiadores demográficos como Philip Curtin obsevaram que, ainda em fins do século XVIII, houve uma melhoria nas taxas de mortalidade do tráfico realizado pelos ingleses que prosseguiu até os anos finais da legalidade do infame comércio. Com a proibição, as rotas marítimas tornaram-se muitas vezes mais longas e arriscadas, causando um maior sofrimento dos embarcados.

Para uma avaliação do que acontecia a bordo dos navios negreiros apreendidos pelos ingleses, mesmo quando já sob comando inglês, temos à disposição alguns relatos de testemunhos oculares, inclusive uma edição brasileira de um escrito pelo reverendo Pascoe Grenfell Hill. Mas, como aponta Barcia, esses relatos, bem como outros documentos por ele utilizados, também 
resultaram da própria conjuntura que permitiu o registro e arquivamento adequado das ações dos oficiais britânicos. Thomas Nelson, por exemplo, foi o cirurgião contratado para dar assistência e observar os cativos recuperados do tráfico na baía da Guanabara. Nelson destacou a presença das principais doenças que atingiam os escravizados transportados pelos navios. A varíola era visivelmente assoladora, juntamente com o escorbuto - também conhecido como "mal de Luanda"- , as disenterias, oftalmias, boubas e diferentes “febres”, como a malária e febre amarela, além de outras doenças, que hoje conhecemos como oncocercose, filariose, a doença do sono.

No primeiro capítulo, o autor trata desses registros médicos, salientando como se criara, ao longo do tempo, uma profilaxia e procedimentos de prevenção contra as doenças ligadas ao comércio marítimo. Baseado nos diversos documentos produzidos por observadores a bordo ou nos portos, o autor sugere que certas perspectivas médicas sobre doenças tropicais já se delineavam no início do século XIX, se antecipando ao ramo da medicina que mais tarde iria se especializar nelas. Surgia ali uma determinada visão sobre o continente africano que enfatizava ser este um ambiente mortífero para os homens brancos, ao tempo em que eram reforçados preceitos higiênicos de regramento moral e físico voltado aos indivíduos, e às medidas sanitárias, tais como a emissão de cartas de saúde, emprego da quarentena, a instalação de equipamentos de ventilação nos navios, medidas que não deixavam também de ser a chave para o avanço colonial europeu na África.

No início do século XIX, a emissão de cartas de saúde, as quarentenas e as vacinações, foram as principais ações sanitárias adotadas ainda que fossem burladas. Como o autor mostra, em diferentes portos dos dois lados do Atlântico, os barracões instalados para receber os "pretos novos” contavam com rotinas e práticas semelhantes. Mas também, invariavelmente, causavam mais mortes entre os cativos recém-chegados. Espraiavam-se as oftalmias, diarreias, doenças de pele, desnutrição, sem contar a presença muda do sofrimento psíquico, silencioso, porém absolutamente visível às testemunhas, devido ao estado de degradação a que eram submetidos os cativos sobretudo durante a travessia. 
Caminhando por diferentes cenários das doenças do tráfico no período da ilegalidade, o autor desloca-se das mudanças efetivadas no campo da profilaxia para, no segundo capítulo, tratar do enfrentamento das enfermidades a bordo dos navios negreiros. Cartas a familiares dos traficantes, listas de remédios das boticas, depoimentos de escravos e proprietários das embarcações apreendidas pela Comissão Mista fornecem ao autor elementos para compreender de que maneira eram enfrentadas as enfermidades e outros sofrimentos dos embarcados, ainda que estes fossem somente mercadoria para a maioria dos autores dessa documentação. Com a superlotação de escravizados nos navios no período da ilegalidade, os traficantes estavam cientes de que o ambiente compartilhado a bordo se tornava mais perigoso. Nesse quadro, Barcia descreve um conjunto de procedimentos médicos e a prescrição de remédios que estariam presentes por todo o Atlântico, demonstrando que os navios eram uma verdadeira "zona de contato" cultural nas mãos de europeus, americanos (no sentido amplo da expressão) e africanos (igualmente). Nas boticas dos navios eram encontrados curativos como o nitrato de prata e o mercúrio para o tratamento das infecções nos olhos e para a sífilis ao lado de plantas medicamentosas provenientes da Europa e da Ásia - tais como o ruibarbo, a camomila e o cardamomo, assim como das Américas, como a ipecacuanha e a quina cuja aplicação na forma de sulfato ou em cascas, era realizada no combate às febres. Tidas como purgativos, adstringentes, eméticos, calmantes ou laxantes, as plantas medicinais eram empregadas pari passu com o que circulava na medicina da época e em manuais muitas vezes encontrados a bordo, indicando o alinhamento entre os diferentes agentes da saúde com certos referenciais comuns, ou seja, um "estilo de pensamento" (para utilizarmos a expressão de Ludwig Fleck) de sua época. Entre os práticos da saúde, Barcia destaca os sangradores de origem africana, cuja presença constante a bordo dos tumbeiros é corroborada nos périplos pelos mares do alufá Rufino, estudado por João José Reis, Flavio Gomes e Marcus Joaquim de Carvalho, e nas listas sobre os embarcados nos 
tumbeiros, conforme os estudos de Jaime Rodrigues. Ainda que o uso de algumas terapêuticas e medicamentos nem sempre funcionasse ou até levasse a uma piora, o que perseverava, era a luta desses homens contra as enfermidades.

O terceiro capítulo aborda as condições de saúde nos navios britânicos em suas investidas na costa africana e o encontro de seus tripulantes com as diversas doenças nos rios que adentravam no intuito de aprisionarem cativos ilegalmente embarcados nos negreiros. É nesse capítulo que o autor discute como a febre amarela se tornou a doença mais terrivelmente letal para as patrulhas de combate ao tráfico. Outras febres, como malária e tifo, eram contraídas também em solo africano pelos europeus. Mesmo que o modo de transmissão dessas doenças fosse ainda desconhecido, levando a debates infinitos entre os defensores das teses miasmáticas e os contagionistas, a presença massiva de mosquitos nos leitos e margens dos rios era tanta, que pareceu natural a um capitão da Marinha britânica, William Owen, estabelecer uma associação destes com o adoecimento dos seus marinheiros no rio Maputo, na década de 1830. O conhecimento dos meios de tratamento das doenças era literalmente vital e as trocas de produtos efetivadas entre os ingleses e os locais incluíram também medicamentos para o combate às enfermidades, não sendo possível, naquelas circunstâncias, abrir mão da experimentação.

O quarto capítulo dá enfoque às condições de saúde nos hospitais e centros de recepção dos africanos liberados em diversos pontos espalhados em ambas as costas do Atlântico. Barcia aborda a debilidade dos recém-chegados, confinados em quarentenas e expostos a outras doenças nos barracões e hospitais, uma vez que os corpos aglomerados, mais a desnutrição e as doenças adquiridas nos tumbeiros, pioravam ainda mais as chances de sobreviverem. Não bastava, assim, serem libertos. Altas taxas de mortalidade eram observadas logo após a chegada dos navios com africanos resgatados das mãos dos traficantes. O autor destaca a opinião de alguns médicos como James Boyle, para quem a taxa de mortalidade dos africanos recém-chegados a Serra Leoa no período de 1808 a 1830 alcançava cerca de um quinto. Em Havana, apesar das 
informações serem menos precisas, segundo o autor, entre 1824 e 1843, no Depósito de Cimarrones, dos cerca de doze mil chegados na cidade, $4,4 \%$ (528 pessoas) não sobreviviam nos dias subsequentes.

No quinto e último capítulo, o autor trata da presença de agentes das artes de curar africanos que atuavam nos barracões e hospitais onde eram tratados os cativos libertados do tráfico. Ainda que indesejada pelos médicos acadêmicos, muitas vezes a presença destes africanos se impôs como a única forma de vencer a resistência dos doentes. Alguns africanos iam estudar na Europa - como o filho de Kafu Bullom, governador dos bulloms nos arredores de Serra Leoa - e retornavam para assumirem seus postos no hospital. Muitos outros práticos africanos dividiam espaço nos centros de acolhimento dos resgatados do tráfico. No rol de africanos que receberam formação em universidades europeias encontra-se James Africanus Beale Horton, de Ibo, que escreveu textos sobre medicina e também o livro West African Countries and Peoples, publicado em 1868, no qual se volta contra o racismo e os estereótipos europeus dos povos africanos. Como Barcia afirma, os práticos africanos participaram ativamente do debate e das trocas de ideias sobre os diversos tratamentos das enfermidades. As situações em que práticos, curandeiros e sangradores estiveram ao lado da medicina ocidental aconteciam em circunstâncias de negociação e com o apoio da população atendida. Ainda que em geral desprezado pelos médicos europeus, havia ocasiões de desespero em que o conhecimento dos africanos prevalecia, como aconteceu no Brasil no caso relatado por Ariosvaldo Diniz sobre a presença de um certo Pai Manuel numa enfermaria em Recife durante a epidemia de cólera em 1855-56. É nesse capítulo que o autor busca demonstrar como novos conhecimentos relativos às doenças e aos tratamentos foram produzidos como "respostas às demandas do tráfico e sua abolição", dando ênfase às trocas efetivadas pelos práticos da saúde e ao que acontecia na costa africana.

William F. Daniell, médico que percorrera a costa da África Ocidental, descreveu na revista Pharmaceutical Journal plantas pouco conhecidas pelos esculápios europeus, como a noz 
de cola, a pimenta da Guiné ou a fruta do baobá, esta última utilizada como cataplasma para combater as dores reumáticas. Outras tantas plantas foram classificadas por viajantes e exploradores, como o português Travassos Valdez, que, anotando os remédios utilizados na região de Luanda, dava a conhecer o muamuá, utilizado no tratamento contra a diarreia, a mussanda para dores de cabeça e o catalango para dor de garganta. Com o acúmulo das informações de ervas medicinais e formas de tratamento de diversos males que afetavam as populações locais, formava-se ao longo do tempo uma nosologia mais apurada de muitas doenças que afetavam todo o Atlântico.

Mas toda a saga das doenças e “demônios” febris apresentada por Barcia não permite estabelecer as trajetórias específicas que apresentaram algumas dessas enfermidades de um lado e do outro do Atlântico. O próprio título do livro - The Yellow Demon of Fever - de início leva a crer numa prioridade quanto à febre amarela na análise, o que não se concretiza. Aliás, não encontrei uma explicação para a escolha do título, a não ser o gosto, muito próprio dos historiadores, de usar uma frase encontrada em algum documento durante a pesquisa, no caso, expressão usada pelo comissário britânico Robert Jameson em Havana para sintetizar o calvário dos homens europeus no Caribe. Talvez a escolha do autor por uma abordagem mais genérica sobre as doenças deva-se a apresentação mais descritiva do que dizem as fontes sobre as mesmas, sem a preocupação em incorporar uma história sobre as relações entre agentes biológicos e humanos. No livro, aqui e ali, são descritas práticas médicas, como a do emprego das fumigações, das desinfecções com vinagre ou cloreto de lima, a utilização do sulfato de cobre e nitrato de prata nas oftalmias, entre outros procedimentos. Mas o autor não se volta para a análise de como o conhecimento dos médicos e práticos da cura sobre os remédios e as enfermidades impactariam na forma de ver a saúde entre as populações sujeitas às doenças. Da mesma forma, vê-se pouco no livro a maneira pela qual esses mesmos agentes correlacionavam as doenças com os tratamentos. Ou, dizendo de outra maneira: se, como afirmou Charles Rosenberg, a doença é ao mesmo tempo um evento biológico, narrativo, cognitivo, político e uma 
experiência subjetiva, podemos forma mais ampla, dentro do universo complementar que ela é, enquanto atlântico, como os agentes envolvidos unidade de compreensão, um "enqua- buscavam debelá-las. Desbravar a dramento” (framing) a partir do qual história da saúde no tráfico transapodemos nomear uma determinada tlântico de escravos requer conhecer doença como, por exemplo, "febre como as enfermidades de milhões amarela”. O autor não aprofunda de pessoas traficadas foram tratadas o debate sobre a compreensão das durante a travessia e como o conhedoenças, nos remetendo diretamente cimento adquirido pelos diversos para os cenários em que elas se desenrolaram, trazendo como principal agentes de cura foram acumulados para salvar vidas, ainda que fosse com contribuição a possibilidade de ver de o pior dos objetivos.

\section{Kaori Kodama (D)}

Fundação Oswaldo Cruz-Fiocruz 